\title{
La convivencia social entre la ética y el pluralismo: "Una perspectiva desde Emmanuel Lévinas"
}

The living social between the ethics and the pluralism: "a perspective from Emmanuel. Lévinas"

\author{
Volumen 18, Número 2 \\ Mayo-Agosto \\ pp. 1-17
}

Este número se publica el 1 de mayo de 2018

DOI: https://doi.org/10.15517/aie.v18i2.33165

\section{Antonio Calderón C.}

Revista indizada en REDALYC, $\underline{\text { SCIELO }}$

Revista distribuida en las bases de datos:

LATINDEX, DOAJ, REDIB, IRESIE, CLASE, DIALNET, SHERPA/ROMEO, QUALIS-CAPES, MIAR

Revista registrada en los directorios:

ULRICH'S, $\underline{\text { REDIE}}, \underline{\text { RINACE}}, \underline{\text { OEI }}$ MAESTROTECA, PREAL, $\underline{\text { CLACSO }}$ 


\title{
La convivencia social entre la ética y el pluralismo: "Una perspectiva desde Emmanuel Lévinas"
}

The living social between the ethics and the pluralism: "a perspective from Emmanuel. Lévinas"

\section{Antonio Calderón $C^{1}$}

\begin{abstract}
Resumen: En términos generales, el presente ensayo se aproxima a la comprensión del fenómeno de la convivencia social bajo dos aristas, el pluralismo y la ética de los ciudadanos. De forma particular, se intenta comprender si es posible vivir juntos y cuáles son las características principales que nos ayudan a saber estar junto al otro. Se analiza y dialoga con algunas características propias del planteamiento que realiza Emmanuel Lévinas, sobre todo, con los elementos de su pensamiento como ser: el dialogo, la responsabilidad, la justicia, la libertad, el respeto (la tolerancia). En un escenario de mucha diversidad, la convivencia social actual se torna como un desafío debido a las muchas exigencias que el ser humano se ha impuesto. Finalmente, en las reflexiones conclusivas, se argumenta la importancia de la apertura y búsqueda de vivir con el otro para mejorar una vida de ciudadanía, y con ella volver a comprendernos como seres humanos y forjar una humanidad con sentido. Humanidad que Lévinas plantea como la ética primera.
\end{abstract}

Palabras clave: pluralismo, ética, responsabilidad, justicia, respeto.

Abstract: In general, terms, the present essay approaches the understanding of the phenomenon of social coexistence under two very relevant edges that are the pluralism and the ethics of the citizens. In particular, it tries to understand the possibility of living together and the main features that help people to know how to be next to each other. It also discusses and dialogs with some characteristics of the approach that performs Emmanuel Lévinas, especially the very relevant elements of his thought as: dialog, responsibility, justice, freedom, respect (tolerance). The social coexistence of today is a challenge, for the many demands that the human being has been imposed today under a scenario of a lot of diversity. Finally, in the reflections it is argued the importance of openness and search of living with another people to enhance a life of citizenship and with its back to understand ourselves as human beings and to forge a humanity with a sense. Humanity that Lévinas presents as the first ethic.

Key words: pluralism, ethics, responsibility, justice, respect.

\footnotetext{
1 Universidad Católica del Maule, Talca, Chile. Académico de la Facultad de Ciencias Religiosas y Filosóficas.
}

Dirección electrónica: acalderon@ucm.cl

Ensayo recibido: 3 de noviembre, 2017

Enviado a corrección: 12 de marzo, 2018

Aprobado: 23 de abril, 2018 


\section{Introducción}

Nuestro siglo se caracteriza por un especial dinamismo en el ámbito de la convivencia social, donde la transformación de los cambios acelerados, económicos, culturales y tecnológicos, genera y exigen una renovación constante frente a las demandas de las necesidades de los ciudadanos que hoy se empoderan validando sus derechos en sociedades democráticas. La realidad de nuestro presente es que estamos insertos en un mundo pluralista y además, tiene que ver con la práctica de la ética en este proceso. Elegimos vestimentas muy diferentes, conseguimos tecnología según los gustos de cada uno. Sin embargo las discusiones sobre política, economía, temas de salud, fútbol, religión, o son muy apasionadas o menos conversadas, esto obedece a que no todos pensamos lo mismo.

A partir de esta experiencia al parecer nuestro mundo en su modo de convivencia también, se halla en una difícil situación, se trata de una "crisis de valores" donde se coloca en estado de riesgo la sana convivencia humana, donde el terrorismo estructural, la injusticia, genera violencia y, por consiguiente, una mayor inmoralidad. Ciertamente, basta con tener la capacidad de lograr una conciencia crítica, sobre acontecimientos muy complejos que aparecen en el horizonte como ser: el crimen organizado, la explotación de niños/as, los adultos mayores que pasan a ser los nuevos pobres en sociedades modernas, las acciones prepotentes de las fuerzas represivas, lo mismo que la práctica de la corrupción en distintas instituciones básicas de un estado.

Esta variedad de fenómenos, donde la violencia institucional establece una guerra no declarada contra los rostros cercanos y a la vez lejanos y los muy lejanos más lejos aún, que se generan con las nuevas tecnologías. Esta situación tiene una característica contemporánea, en la que se genera una violencia enmascarada por la difusión del mal llamado Nuevo Orden Mundial en la que proliferan distintas medidas económicas o políticas que ahondan la desigualdad entre clases sociales, entre países y entre regiones del mundo. El derecho a una vida digna es una tarea de cada miembro de la sociedad, su búsqueda y desarrollo debe ser muy reflexionado para convivir mejor.

El presente ensayo tiene la finalidad de analizar algunas ideas acerca del planteamiento de Emmanuel Lévinas para poder comprender nuestra tarea de convivir con el otro en el día a día, considerando el rostro del otro como esencial para comprender nuestra humanización y así considerar una convivencia social adecuada a nuestros tiempos. 


\section{2. ¿Es posible vivir juntos?}

Es una pregunta de fácil respuesta para unos si obedece a que la sociedad está bien y sigue su curso sin ningún cambio o si existe cambio es manejable y gobernable. En cambio para otros la respuesta puede ser negativa por la complejidad de la sociedad globalizada ${ }^{2}$ en que hoy se encuentra nuestra realidad y que genera incertidumbres en el marco societal que vivimos. ${ }^{3}$ Es decir hay un modo de vivir los valores los cuales están afectados por la diversidad $^{4}$, a su vez esta se enmarca en el pluralismo, el cual se reconoce en un mundo complejo de convivencia. Sin embargo, es importante describir lo que entendemos por pluralismo, ella se refiere a la abundancia y multitud de cosas que se interrelacionan, como ser doctrinas, ideas, religiones, culturas, etc., los cuales apuestan a ser y estar dispuestos a convivir entre esta diversidad plural. Una de las consideraciones esenciales es que el pluralismo entra a ser un valor, porque contiene importancia con los sistemas democráticos, son ellas las que imprimen el derecho a la participación ciudadana con sus modos y sus diversas formas de vivir. Ella promueve y propicia el vislumbramiento de las minorías y de las mayorías como distintos y diversos grupos sociales. Ya que la puesta en práctica de este valor genera la existencia y coexistencia entre las mayorías y las minorías de conglomerados sociales, los cuales tienen diferencias entre sí, sin embargo apuestan por la capacidad de vivir y convivir incluso llevando a una postura muy radical de libertad o de soledad como plantea Rojas ${ }^{5}$, ilimitada como destaca Lipovetsky ${ }^{6}$. Lo más interesante del pluralismo es la

${ }^{2}$ La estrategia de globalización y, con ella, el crecimiento exorbitante de las burocracias privadas, sigue nada más una lógica de la maximización de las ganancias y con eso, la abolición de los derechos humanos más elementales. El criterio de la maximización de las ganancias tiene que ser canalizado por el respeto a los derechos humanos con el efecto de que no debe ser más que un criterio secundario. Sin duda, se trata de un conflicto social que hay que asumir, pero este conflicto no se puede tratar exclusivamente como un conflicto de clases. En este conflicto se trata más de dominar y controlar las burocracias privadas que están amenazando a la humanidad. Por tanto, se trata de un conflicto sobre la sobrevivencia de la humanidad entera (Hinkelammert, 2012, p. 102)

3 Vivimos una crisis más profunda que un acceso de miedo o desencanto; percibimos como, en nosotros y a nuestro alrededor, se separan, se disocian, por un lado el universo de las técnicas, los mercados, los signos, los flujos, en los cuales estamos sumergidos, y, por el otro, el universo interior que cada vez con más frecuencia llamamos el de nuestra identidad. La afirmación más fuerte de la modernidad era que somos lo que hacemos, nuestra vivencia más intensa es que ya no es así, sino somos cada vez más ajenos a las conductas que nos hacen representar los aparatos económicos, políticos o culturales que organizan nuestra experiencia. Algunos arrojan al flujo de las informaciones y los productos de la sociedad de masas; otros procuran reconstruir una comunidad que proteja su identidad, filtrando las incitaciones provenientes de la producción, el consumo o la comunicación masiva. Pero la inmensa mayoría pertenece y quiere pertenecer a uno y otro universo. (Touraine, 2006, p.27)

${ }^{4}$ En el interior de la misma comunidad política democrática han de coexistir y convivir diversas formas de vida cultural, religiosa y étnica, entonces la cultura mayoritaria debe estar suficientemente desvinculada de su tradicional fusión - explicable históricamente - con la cultura política compartida por todos los ciudadanos. (Habermas, 1999, p.142)

${ }^{5}$ El texto el Hombre Light relata que la soledad y la comunicación interior suelen formar una estructura que en el hombre light no se da y en la que hay banalidad, porque no se interroga nada trascendente que lo obligue a 
capacidad de enriquecer a la sociedad en todo sentido, cuando se la considera como un valor con sentido, si es que se considera que solo podemos vivir juntos y además se reconocen las diferencias y al mismo tiempo nos reconocemos mutuamente como seres humanos en una era globalizada. Por otro lado, no se puede entender el pluralismo en el campo de la ética, en la que las normas y valores morales se siguen expresando como lo absoluto por ciertos poderes autoritarios como indica Touraine ${ }^{7}$, porque hoy ya no se juzga las acciones de las personas como lo definitivo. Esto obedece a que en nuestro contexto el pluralismo está relacionado con otros valores en la que se aceptan las capacidades de los ciudadanos que piensan de modo diferente. Con todo esto, nos acercamos a ver qué pasa con el otro en la proximidad real de su presencia.

E. Lévinas en su aporte, tiene un enfoque ético-filosófico el cual se basa en tres fuentes muy importantes: "la influencia religiosa de su tradición judía; la relevancia filosófica de la fenomenología husserliana y el padecimiento trágico y determinante del holocausto judío"8 plantea una relación metafísica de la epifanía del Otro en el rostro, eso significa en la manifestación del otro:

El rostro se niega a la posesión, a mis poderes. En su epifanía, en la expresión, lo sensible aun apresable se transforma en resistencia total a la aprehensión. Esta mutación solo es posible por la apertura de una dimensión nueva (...) la expresión que el rostro introduce en el mundo no desafía la debilidad de mis poderes, sino mi poder de poder. El rostro, aun cosa entre cosas, perfora la forma que, sin embargo, lo delimita. Lo que quiere decir concretamente: el rostro me habla y por ello me invita a una relación sin paralelo con un poder que se ejerce, ya sea gozo o conocimiento. (Lévinas, 1978, p. 211)

replantearse la existencia de otro modo. Es una soledad sin rebelión personal y sin análisis. Por otra parte, la relación con el otro está muy resquebrajada (Rojas, 1995, pp. 93-94)

6 Vivir libremente sin represiones, escoger íntegramente el modo de existencia de cada uno: he aquí el hecho social y cultural más significativo de nuestro tiempo, la aspiración y el derecho más legítimos a los ojos de nuestros contemporáneos (Lipovetsky, 2008, p. 8)

7 Los poderes autoritarios tienen la voluntad de unificar culturalmente la sociedad para imponer un control absoluto a unos individuos y grupos cuyos intereses, opiniones y creencias son siempre diversos (Touraine, 2006, p. 166)

8 Véase en Quintero, 2014 
Es decir, se trata del cara a cara, que es ir más allá de la exterioridad ${ }^{9}$, es el Otro que rompe la soledad que plantea Rojas para nuestro tiempo con el "Hombre Light", donde la existencia con el rostro del Otro está en juego. De ahí que el pluralismo tiene relación con varios valores que se pueden vislumbrar en tiempos democráticos como ser la responsabilidad, la justicia, la libertad, y la tolerancia.

\subsection{El Pluralismo y responsabilidad una necesidad para convivir}

En una sociedad plural, toda persona está en su derecho y tiene la libertad de pensar, expresarse de acuerdo con sus convicciones, sin embargo, también debe ser capaz de aceptar y reconocer aquellas consecuencias que emergen de esta vivencia (Gimeno, 2002, p.197). Lévinas indica que nuestra relación con el otro no es objeto de comprensión y después un ser locutor, lo que se debe tener en cuenta y con claridad es que el otro no es inseparable de su comprensión, es decir:

El pluralismo no es una multiplicidad numérica. Para que se realice un pluralismo en si (...) es necesario que se produzca en profundidad el movimiento de mí al otro, una actitud de un yo frente al Otro (...) El pluralismo supone una alteridad radical del otro que yo no concibo simplemente en relación a mí, sino que afronto a partir de mi egoísmo. Accedo a la alteridad del otro a partir de la sociedad que yo mantengo con él. (Lévinas, 1978, p. 140)

En otras palabras, de aquello que se entiende por lo diverso, por lo cual se entiende que la relación social no tiene que ver con una relación cualquiera o una más que se producen en la persona en el día a día, sino que es una relación de un hecho en sentido último. Y por ello entiende el Filósofo que en la relación metafísica se realiza un existir múltiple, el pluralismo (Lévinas, 1978, p. 233), Esta multiplicidad tiene un objetivo claro que es la reflexión total sobre la imposibilidad de que se produzca una confusión en un todo el yo y el no yo, esta imposibilidad tiene que ver con la excedencia de la manifestación del Otro, donde la sensibilidad viviente, que come, que duerme, está presente quedando así constituida como una ética por la experiencia que se realiza en el cara a cara que me invita a ser responsable. Responsabilidad ante su rostro que me interpela porque como ser humano está la sensibilidad, que para Zubiri, estamos capacitados como seres con inteligencia

\footnotetext{
9 La imposibilidad se debe a la excedencia de la epifanía del Otro que me domina desde su altura. " Totalidad e infinito" (Lévinas, 1978, p.234)
} 
sentiente $^{10}$, y que el ser humano tiene la capacidad de sentir la realidad ${ }^{11}$. De este modo Lévinas presenta su pensamiento en sus obras ${ }^{12}$ que la responsabilidad es la estructura esencial, primera y fundamental de la subjetividad. De tal manera que la responsabilidad es para con el otro, incluso para con aquello que no es asunto de uno o no concerniente que debe ser llevado y configurado por una obligación por la existencia del otro y visto como para el rostro del Otro. En sentido muy claro la presencia del otro, a quien no lo invite a estar en esta historia, que camina al lado mío y me mira yo soy responsable de él, aunque el otro indique que no tengo nada que ver con las responsabilidades suyas. Es decir la responsabilidad es prácticamente un valor que va más allá de lo que hace uno. Una responsabilidad entendida desde la proximidad donde el rostro del otro pide y ordena.

La responsabilidad como la estructura esencial, primera, fundamental de la subjetividad. Puesto que es en términos éticos como describo la subjetividad. La ética, aquí, no viene a modo de suplemento de una base existencial previa; es en la ética, entendida como responsabilidad, donde se anuda el nudo mismo de lo subjetivo.

Entiendo la responsabilidad como responsabilidad para con el otro, así, pues como responsabilidad par con lo que no es asunto mío o que incluso no me concierne; o que precisamente me concierne, es abordado por mí, como rostro. (Lévinas, 1991, p. 89)

La tarea no es fácil, ser responsable de todo lo que encontramos en este mundo, es dejar para las nuevas generaciones un camino en la que ellos también se hagan cargo de su presencia en este mundo. Ahora bien, todos los seres vivos no hablan de ética y responsabilidad, solo el ser humano, tiene esa característica y porque, sus acciones, sus actos están facultados para ser y tener la capacidad de cultivar ciertos límites que no afecten su vida y su vida social en esta historia. Eso significa buscar la mirada de una relación de aceptación y tolerancia en todo sentido.

\footnotetext{
10 El ser humano está en la realidad con toda su potencialidad, de ahí que Zubiri indica que la unidad estructural de inteligencia y sentir es determinante de la habitud de intelección sentiente cuyo acto formal es la impresión de la realidad. En cuanto determinante de esta habitud, la estructura unitaria 'sentir - inteligencia', es la facultad de inteligencia sentiente. Por ello es por lo que el hombre siente impresivamente la realidad. Tratase, pues, no solo de habitud sino de estructuras. Por esto es, repito, por lo que la intelección es un acto de aprehensión sentiente de lo real. (Zubiri, 1991, p. 96)

11 Véase como Zubiri explica que la impresión de la realidad tiene una gran complejidad, porque cada sentido siente la formalidad de la realidad de un modo distinto (...) no se trata de distintas impresiones de realidad sintéticamente reunidas, sino de distintos momentos de la única impresión de realidad. Por esto, esos momentos parcialmente se recubren. Especialmente, el momento del hacia recubre a todos los sentidos: es la presencia direccional de la realidad. (Zubiri, 2003, p. 35)

12 Ver en Lévinas 1998.
} 


\subsection{El Respeto (La tolerancia) una forma de vivir contemporáneamente}

Nuestra observación sobre el pluralismo es que todas las posturas son válidas, pese a la existencia de diferencias, puesto que enriquecen e impulsan el desarrollo de la sociedad. En cambio el respeto (la tolerancia ${ }^{13}$ ) permite que los individuos y los diversos grupos puedan convivir libremente con sus diferencias, con la manifestación del respeto y la consideración de beneplácito hacia las opiniones y prácticas de los demás. En se aspecto Touraine plantea que solo podemos vivir juntos con nuestras diferencias si nos reconocemos mutuamente como sujetos. (Touraine, 2006, p. 166). Sin embargo, Lévinas se refiere a la vivencia en proximidad, y esa proximidad es la alteridad del Otro que como rostro se manifiesta rompiendo con el mundo por ser ella el lugar común en la que naturalmente nos encontramos por la existencia, en consecuencia el filósofo indica que:

...la relación con el rostro, con el otro absolutamente otro que no podría contener, con el otro, en este sentido, infinito, es sin embargo mi idea, un comercio. Pero la relación se mantiene sin violencia, en paz con esta alteridad absoluta. La resistencia del otro no me hace violencia, no obra negativamente; tiene una estructura positiva: ética. La primera revelación del Otro, supuesta en todas las demás relaciones con él, no la captara en su resistencia negativa, no lo engaña con astucia. No lucho con un dios sin rostro, sino que respondo a su expresión, a su revelación (...) El rostro me habla y por ello me invita a una relación sin paralelo con un poder que se ejerce, ya sea gozo o conocimiento". (Lévinas, 1978, pp. 210-211)

Así el valor del respeto tiene que ver con un trato de bienestar al otro que se manifiesta y que se revela. Es decir, pensar en las consecuencias de los propios actos y además es integrar las diferencias o la diversidad de los otros; para una cohesión social donde se hace necesario el respeto como un mínimo. Por otro lado, para una vida democrática y auténtica es indispensable actuar con criterio propio, tener capacidad de dar razón de nuestras acciones y estar dispuestos a comprender la posición de los otros. Para poder vivir juntos

\footnotetext{
${ }^{13}$ Según la RAE tolerar (del latín tolerare) significa sufrir, llevar con paciencia, permitir algo que no se tiene por licito sin aprobarlo expresamente, resistir o soportar; lo mismo ocurre en francés (tolérer), ingles (to tolerante) 0 alemán (dulden). Esto es alguien tolera algo que es amenazante o dañino para el propio ser, algo diferente 0 extraño a la propia identidad, a lo que no es conocido o nos sienta bien. Pero frente a la tolerancia del soportar se sitúa la tolerancia del comprender; una vez que se da el paso de querer superar las diferencias, el rechazo visceral del otro, de lo otro nos encontramos ya en el terreno racional de a tolerancia positiva. (Roldan, 2015, p. 113).
} 
debemos entender que el Otro nos envuelve en su alteridad ${ }^{14}$. Esta envoltura tiene sentido para que podamos sentirnos acogidos y tener la capacidad de acoger a todos, ahora bien no solamente es suficiente tener buenos sentimientos; sino que se debe saber generarlos y expresarlos: mostrando amabilidad, agradecimiento y generosidad.

\subsection{El ejercicio de la libertad en tiempos de pluralismo}

En una sociedad donde la práctica del pluralismo se establece como esencial, le permite a los individuos que integran esta sociedad contar con la posibilidad de actuar de manera libre, es decir que se debe comprender siempre dentro de determinados límites, de tal forma que no se violenten los derechos de los demás. De ahí que la libertad es el subproducto de la vida (...) ser libre es construir un mundo en el que se pueda ser libre (Lévinas, 1978, p. 183) para la vida en relación de sociedad, es necesario comprender esta libertad, libertad conquistada por muchos a costa de su vida. Por lo tanto, el individuo no puede evadir su responsabilidad de ejercer su libertad pero viviendo en sociedad. Este aspecto no es nada más y nada menos que ejercer su derecho y a:

...una posición que le ponga a salvo del orden inmediato de las necesidades inscritas en las leyes naturales que gobiernan a las cosas, a los seres vivos y a los seres pensantes en una Naturaleza que, no obstante también engloba y comprende en cierto sentido a los humanos. (Lévinas, 1993, p. 243)

Solamente se puede comprender el pluralismo cuando los individuos mutuamente reconocen que la libertad es indispensable para poder convivir en una sociedad llena de tensiones y debates. Es decir, la libertad y el pluralismo deben ser unos principios mínimos para la expresión de la libertad y la diferencia, valores que deben complementarse con la igualdad, entendida como equidad, como el derecho a tener derechos. Ahora bien si existe la diferencia, ella nos debe proyectar a la diversidad, la cual se enriquece con la expresión de otros valores como ser: la justicia, la solidaridad, los cuales se concretizan por medio de prácticas en buscar la equidad, la cooperación y de compartir, buscando la justicia, basada en el respeto. Estos valores solo se entienden cuando existen condiciones para generar verdaderos proyectos de vida ciudadana.

\footnotetext{
${ }^{14}$ Esta alteridad, esta separación absoluta se manifiesta en la epifanía del rostro, en el cara a cara. Se trata de una unificación completamente distinta de la síntesis, pues instaura una proximidad diferente de la que regula la síntesis de los datos y los reúne en un mundo de partes de un todo. (Levinas, 1993, p. 215)
} 
Es decir, el Otro, desde Lévinas, no contribuye a limitar la libertad del Mismo. Cuando evoca la responsabilidad lo que hace es entregarle sentido y justificar la promoción de la libertad como parte de la bondad. Por lo tanto, la relación con el Otro tiene una característica especial que es la de una obligación. Esta obligación tiene un sentido claro sobre lo que es la responsabilidad para con el Otro, es un compromiso más real que otra deliberación memorable y constitutiva del humanismo. El ser humano de nuestra contemporaneidad no tiene la capacidad y posibilidad de generar en el otro una mirada más profunda, aun teniendo su cercanía. Ahora bien esta cercanía hacia el Otro no tiene la intención de cosificarlo o solamente sea un dato más; sino que tiene una orientación relacional de una cercanía más humana y por ello, no puede ser una relación de conocimiento, sino que es una relación muy elemental en la que se considera el sentido ético, de ahí que el Otro posee una importancia mayor, esta exigencia es que me encargue de él, pese a que yo no lo haya elegido a que este conmigo en esta historia.

Ahora bien la tarea de la relación del yo con el Otro de ninguna manera debe ser una conceptualización. Eso quiere decir que la reducción del Otro al Mismo en el planteamiento de Lévinas es de una obligación de humanismo: Es un humanismo de la afirmación de uno mismo en el interior de la afirmación del otro. Que Hinkellammert asume actualmente, como un humanismo de la afirmación del ser humano como sujeto en relación a los otros y a la naturaleza (Hinkelammert, 2012, p. 205). Por tanto, la relación no se da desde del sujeto hacia el Otro, como una decisión por la libertad que poseo, sino que su dinamicidad es que viene originalmente hacia mí. Así, Lévinas saca a la filosofía del lugar planteado por mucho tiempo que es la subjetividad, del "yo pienso", situándola y plasmándola en mera pasividad. Es una pasividad que antecede a la libertad, la cual no permitiría establecer la impugnación como un "yo puedo". Esta pasividad natural del Bien que no permite la elección. Esto significa que existe una imposibilidad moral de exigir al Otro lo que me exijo a mí mismo. Así, Lévinas saca a la filosofía del lugar planteado por mucho tiempo que es la subjetividad, del "yo pienso", situándola y plasmándola en mera pasividad. Es una pasividad que antecede a la libertad, la cual no permitiría establecer la impugnación como un "yo puedo". Esta pasividad natural del Bien que no permite la elección. Esto significa que existe una imposibilidad moral de exigir al Otro lo que me exijo a mí mismo. 


\subsection{La justicia como baluarte de una sociedad más justa en tiempos de Pluralismo}

La justicia tiene una estrecha relación con el pluralismo, porque tiene la facilidad de ayudar en la transmisión de saberes y creencias con relación a una gran cantidad de concepciones que cada sociedad tiene acerca del bien común. Puesto que la mayoría de las sociedades hoy se enfrenta a la necesidad de mantener una armonía equilibrada entre sus integrantes y ciertamente que para plasmarlo tiene que establecer normas claras en las interacciones entre sus miembros, producto de un consenso y de coordinación amplia sobre lo bueno y lo malo.

Ahora bien, la justicia viene a ser la responsabilidad sobre el rostro del Otro:

Es un hacerse cargo del destino de los otros [...] Aquí, la justicia es anterior, pues, al hacerse cargo del destino del otro. Debo aportar un juicio allí donde tenía antes que aceptar responsabilidades. Entonces asistimos al nacimiento de lo teorético, de la preocupación por la justicia, que es el fundamento de lo teorético. Pero la justicia aparece siempre a partir del Rostro, a partir de la responsabilidad respecto de los demás, e implica juicio y comparación, comparación de lo que es principio es incomparable, pues cada ser es único, cualquier otro es único. Con esta necesidad de ocuparse de la justicia aparece la idea de equidad, en la que descansa la idea de objetividad. (Lévinas, 1993, pp. 129-130)

Ahora bien este hacerse cargo, para Bauman dentro de la contemporaneidad indica que no es fácil su comprensión, ya que vivir en sociedad es para vivir juntos, y por ende, la socialización persigue unos fines, donde la sociabilidad es un fenómeno de estética y por ello propone la proximidad con el otro, como elemento fundamental de la cercanía (Bauman, 2004, pp. 149-150) y también, aborda sobre la justicia que se da entre las persona ${ }^{15}$, en tanto que los juicios vinculan la voluntad, como el efecto de una conducta de vida consciente. Que en Habermas se manifiesta la libre voluntad en sentido ético (Habermas, 1999, p. 57).

Una de las propuestas de Lévinas es la capacidad de comprensión entre los seres humanos en la perspectiva de ser capaces de generar una justicia porque el otro me exige, su sola presencia ya me obliga a emplear la justicia en el sentido de equidad. Si bien las

\footnotetext{
${ }^{15}$ Cada persona es capaz de hacer una elección moral, y ello nos permite tratarla como la destinataria de una exigencia moral y como sujeto moralmente responsable [...] la mayoría de las personas, al hacer la elección, no eligen lo que es moralmente bueno. Paradójicamente, es esa libertad de juzgar y elegir necesita de una fuerza externa que obligue a una persona a hacer el bien... ( Bauman, 2004, p. 36)
} 
sociedades avanzaron en este tema sobre la equidad en el género femenino y masculino existe un gran avance, sin embargo, la equidad en materia de salarios aun no son muy alentadores, puesto que aún no existe justicia en este tema. Por otro lado la justicia en muchas sociedades occidentales aun no queda resuelto, por el no reconocimiento aun de los Derechos Humanos como establece las Naciones Unidas, en muchos pueblos o sociedades modernas la justicia no cumple con su rol de compromiso real. Que es velar por la dignidad y derechos de muchos migrantes. Por lo que el pluralismo pese a estar presente, aun no es comprendido. Es necesario considerar que cada cual pueda enriquecer este mundo como es, con su identidad con su epifanía como pueblos y seres humanos que tratan de vivir en coordinación unos con otros valorándose, respetándose y activando la justicia en los momentos necesarios.

\section{La epifanía (manifestación del otro) un desafío para una ciudadanía comprometida}

Una de las apuestas de la ética, es su acción frente a la responsabilidad sobre el otro. Esta acción se realiza solo en la manifestación del Otro. De ahí que Lévinas tiene una inquietud acerca de esta tarea en su época, es la acción por un mundo que viene, superación de su época: superación de sí que requiere la epifanía del Otro. Es decir, que la ceguera de la ética fundamental se ubica en reducir toda acción inmediata, bajo un egoísmo de situar una ciudadanía sin compromisos por la vida del otro.

Entonces cabe la pregunta, para nuestros tiempos ¿Cuál es la importancia de la ciudadanía y como esta es de compromiso? La ciudadanía indica Kymlicka es:

Una sociedad que reconoce los derechos diferenciados en función del grupo, los miembros de determinados grupos se incorporan a la comunidad política no solo como calidad de individuos, sino también a través del grupo, y sus derechos dependen, en parte, de su propia pertenencia de grupo (...) la ciudadanía debería ser un foro donde la gente superase sus diferencias y pensase en el bien común de todos los ciudadanos. (Kymlicka, 2015, pp. 240-241)

La sociedad democrática necesita cuidar los derechos, porque el individuo busca mantener o elegir la cultura donde quiere realizarse y desarrollar su vida, es decir, pertenecer a otro grupo, que lo acepta, sin embargo, pese a ello existe vulnerabilidades en todo sentido, por eso la sociedad activa la justicia social. 
Ahora bien, una de las preocupaciones que tiene Lévinas es el hecho mismo de la vulnerabilidad del otro y que se ve en el rostro como un ser frágil e indefenso que se encuentra expuesto a otro ser que trae una perspectiva egoísta en esta ciudadanía. Es decir, nos referimos al otro ser humano, que se encuentra en el abandono, en el olvido, con carencias de ciertas necesidades a tal punto de desaparecer. Por lo mismo Lévinas recurre y considera imágenes bíblicas de la debilidad, como ser la viuda, el pobre, el huérfano y el extranjero para referirse a la vulnerabilidad del rostro. Por lo mismo, en nuestro contexto cabria la pregunta de ¿quiénes son esos rostros? y al parecer las imágenes aun se repiten por ejemplo: se remplaza al adulto mayor por el de la viuda, el migrante de color y de distinta etnia, por el extranjero, el huérfano por los niños y jóvenes que caen en el abismo de las drogas, abandonados a su suerte, los sin tierra, sin vivienda, sin educación y sin cobertura de salud es el pobre que se debate entre la suerte de este mundo que se jacta de haber logrado muchos avances científicos y tecnológicos, sin embargo, en materia de humanismo y humanidad dista de ser una sociedad avanzada y civilizada ${ }^{16}$. Dada esta comprensión de la vulnerabilidad del rostro del otro ser humano, Lévinas indica acerca de ella como la capacidad que tiene el sujeto egoísta de ser afectado o herido éticamente ante la presencia necesitada del rostro de su más cercano prójimo. Es decir, el rostro del otro se expresa, en aquello en que no es necesario porque formular literalmente una disertación y utilizar palabras articuladas con el uso de tecnicismos sobre lo que es, sino que basta su silenciosa presencia para expresar su vulnerabilidad y a la vez un mandato u obligación, esto es, prohibir el asesinato o, lo que es lo mismo, obligar a hacer todo lo posible para que él siga viviendo y expresándose. Jiménez dice que "no sólo somos hijos de los griegos, sino también de la Biblia"17. La ciudadanía entendida desde nuestra contemporaneidad debe tener esa capacidad de considerar la presencia del otro, es decir, entender el valor de la diversidad cultural como plantea Kymlicka:

La argumentación de la diversidad resulta más plausible como defensa de los derechos polietnicos de los grupos étnicos. A diferencia del gobierno nacional, estos derechos contribuyen directamente a la diversidad en el seno de la cultura mayoritaria. Además, no implican el mismo tipo de restricciones sobre la movilidad o las

\footnotetext{
${ }^{16}$ Las democracias modelo de Occidente, al basar su política en la estrategia de globalización, destruyen las bases de la vida en gran parte del mundo. Para poder hacerlo en un ambiente de estabilidad, necesitan a los regímenes de fuerza en muchas partes del mundo para aplacar las posibles resistencias, y los promueven. ( Hinkelammert, 2012, p.197)

17 Gil Jiménez, P. (2006). En la Biografía de Emmanuel Lévinas se encuentra su trayectoria intelectual. Ver en la Web: http://deautores.blogspot.com.co/2006/08/teora-tica-de-lvinas.html
} 
oportunidades económicas de la mayoría. (...) Aquí se plantea de nuevo el problema de que hay muchas maneras de fomentar la diversidad. Enseñar a los niños a que sean bilingües fomenta la diversidad, pero esto no puede explicar por qué deberíamos enseñar lenguas de los inmigrantes en particular. Por consiguiente la argumentación de la diversidad completamenta, pero sustituye, a las argumentaciones de justicia basadas en la igualdad o en el acuerdo histórico. (Kymlicka, 2015, p.173)

Por lo tanto, los ciudadanos deben tener un nivel muy alto de razonabilizar la diversidad y el pluralismo con moderación y fomentar la solidaridad mutua, las muchas reivindicaciones que aparecen hoy son de necesidades fundamentalmente de inclusión como plantea Habermas ${ }^{18}$, como el elemento esencial, para el logro de una participación equitativa en el conjunto de la sociedad actual.

De esta manera, se entiende que el compromiso básico de una democracia es la libertad y la igualdad de sus ciudadanos individuales. Esto tiene asidero en los derechos constitucionales, que garantizan los derechos civiles y políticos básicos a todos los individuos, independientemente de su presencia y pertenencia a un grupo. La relación entre este tipo de ciudadanía y los derechos individuales es, de hecho, bastante compleja. Pero no imposible de realizar lo que Habermas propone es el dialogo entre todos para converger en garantizar las muchas necesidades que hoy son afectadas de modo sistémico. Este dialogo solo se comprende en el tiempo por medio de la educación:

Somos los únicos seres capaces de ser objeto y sujeto de las relaciones que trabamos con los otros y con la historia que hacemos y que nos hace y rehace. Las relaciones entre nosotros y el mundo pueden ser percibidas críticamente, ingenua o mágicamente percibidas, pero hay en nosotros una conciencia de estas relaciones en un nivel que no existe entre ningún otro ser vivo con el mundo (...) En este sentido la conciencia de la practica implica la ciencia de la practica implícita o anunciada en ella. De esta forma, hacer ciencia es descubrir, desvelar verdades sobre el mundo, los seres vivos y las

\footnotetext{
18 La ética discursiva justifica el contenido de una moral del igual respeto y responsabilidad solidaria para con todos (...). Doy por supuesto que los interesados no quieren dirimir sus conflictos mediante la violencia o el compromiso, sino mediante el entendimiento. En ese caso es lógico que primero intenten llevar a cabo deliberaciones con objeto de desarrollar un autoentendimiento ético común sobre una base profana. Sin embargo, en las condiciones de vida diferenciadas de las sociedades pluralistas, semejante tentativa tiene que fracasar. Los interesados aprenden que el cercioramiento critico de sus valoraciones fuertes y garantizadas por la practica conduce a concepciones del bien que compiten entre sí. Supongamos que se mantienen firmes en el objetivo de alcanzar un entendimiento y que, además, tampoco quieren sustituir por un mero modus vivendi la convivencia moral que se halla en peligro. (Habermas, 1999, pp.70-71)
} 
cosas, que descansaban a la espera de ser desnudadas. Es darle sentido objetivo a algo que nuevas necesidades emergentes de la práctica social plantean a las mujeres y a los hombres. (Freire, 2006, pp. 112-113)

Aquí aparece una propuesta antropológica-pedagógica donde el hacerse cargo por el otro no es desde las simples intuiciones, sino que esta se debe abordar desde la misma realidad, el hacerse cargo desde la manifestación del rostro del otro como una alternativa es para abordar los problemas desde la educación. Frente a un mundo de cambios vertiginosos y, que una sociedad pluralista, se plantea constantemente la supremacía del sujeto individualista como responsable de su desarrollo y de su bienestar económico, en detrimento de otros seres humanos debido a muchas causas del momento no logran salir por sus propios medios y esfuerzos de una realidad donde la indigencia, el abandono, la manipulación y dominio de los que tienen el monopolio económico, los medios de comunicación, son causa de marginalizaciones en pleno siglo XXI.

Justamente el rostro del Otro nos protesta desde la marginalidad, nos invita a la pedagogía a salir a la periferia del deshumanismo, porque la práctica educativa es muy seria y ella debe contribuir a la búsqueda de un desarrollo humano con sentido. Esto obedece a que se trata con personas: niños, adolescentes, adultos. Su tarea es contribuir con seriedad y ser testimonio de la búsqueda de la verdad, la libertad, es decir, la responsabilidad por los derechos humanos, es hacernos cargo del otro responsablemente y por ello debemos plantearnos una responsabilidad para el otro. Esto se entiende en que el Otro es una sensibilidad corpórea, por lo tanto la subjetividad, en cuanto observa su realidad como un yo sensible y que esta se encuentra en la misma naturaleza humana, ya posibilita un nexo ético. En la misma línea Zubiri plantea que los seres humanos somos inevitablemente morales por ser inevitablemente libres (Zubiri, 1998, p.17). Por lo tanto, este modo de comprensión de la subjetividad se mantiene alejado claramente de la conciencia que es conciencia de ser. De tal manera, que el rostro del otro no menciona una exigencia moral de tener conciencia acerca del otro. En lugar de recurrir a la conciencia, el rostro del otro constituye entre el mismo y el otro la dimensión de la subjetividad indispensable para la convivencia humana en contexto pluralista.

En consecuencia, el sujeto en Lévinas es sensible, porque el rostro del otro no se refiere a la parte externa del ser, como el conjunto de aspectos: una nariz, una frente, unos ojos, etc., es por cierto todo eso, sin embargo, va más allá de esa exterioridad, que se trata 
de la significación de un rostro por la dimensión nueva que abre en la percepción de un ser. El rostro determina que el ser esté no sólo encerrado en la forma y ofrecido al alcance de la mano, sino abierto, instalado en profundidad y, en esta apertura, se presenta en cierto modo personalmente. Se trata de una presencia frente a un rostro, una presencia abierta y generosa incapaz de aproximarse al otro con las manos vacías. En la actualidad, sería de gran valor sensibilizarse para la responsabilidad y para la ética de la subjetividad en el contexto de globalización. La educación está llamada a una búsqueda de reencuentro del hombre con su humanidad. Se puede decir que la educación es una posibilidad a ser construida en el encuentro y acogimiento del otro.

\section{Reflexiones finales}

El presente ensayo nos muestra una apertura, hacia un nuevo camino que Lévinas sugiere para la ética y la nueva forma de convivir en nuestra sociedad pluralista. Plantea que a partir del diálogo y la comprensión del otro se elabore una conversación cruzada desde la crítica y la acogida se pueda vislumbrar una tarea de saber convivir con el otro a quien no lo he invitado a vivir esta historia.

Una cosa esta clara, Lévinas ya cargo sobre sus espaldas el problema de la subjetividad y su disolución que bien establece Nietzsche, y junto con ello el punto de vista sobre la cuestión del humanismo en Heidegger, pese a ello, frente a esos problemas existe aún algo más dramático, se trata sobre la disolución de la subjetividad que conlleva una disolución o un relativismo de la ética. En consecuencia, ya no cabe la posibilidad de formular un proyecto ético considerando o teniendo a la vista un sujeto moral, como el que plantea Kant, porque la conciencia tendría una situación situada en el egoísmo. De esta manera se pone en tela de juicio el supuesto camino de la postmodernidad a la postmoralidad, en la que Lévinas consideraría como asimilación comprometida por el Otro, en la que introduce la afirmación de la extinción del yo como la equivalencia al desaparecimiento del Otro, toda vez que ese Otro es negado o anulado en su alteridad esencial es percibido simplemente como otro-yo. Frente a esta situación o alternativa, es posible comprender el pensamiento levinasiano como la capacidad de un intento por rescatar la vida de la ética en el contexto de la descentralización del sujeto y del modo que vive hoy que es plano del pluralismo. Es decir, Lévinas tiene una oposición radical al imperialismo y al monopolio del sujeto, además no pierde de vista aquello que descentra al yo frente a la radical alteridad del Otro, por lo que la verdad de la relación ética, debe ser la vivencia de un 
humanismo en donde no existe lugar la afirmación del otro como un medio sino que es el fin en sí mismo, donde se hace legitimo un claro planteamiento de un sujeto totalmente responsable por el Otro, el cual es un fin y esa alteridad crea un rehén de un deber perpetuo hacia él. Por lo tanto, la ciudadanía se comprende desde un compromiso hacia la apertura de la alteridad generando un humanismo mucho más claro y de responsabilidades en conjunto.

Finalmente es llegar a vivir un humanismo y una humanidad donde se experimente la esperanza metafísica del Otro, esa esperanza insaciable, más allá de toda falta o necesidad terrenal. Por consiguiente, la metafísica ética de Emmanuel Lévinas nos devuelve la esperanza en la posibilidad de lograr un encuentro del uno con el otro en el marco de la vida en socialidad. (Jiménez 2006) ${ }^{19}$. Este es el punto de encuentro de un humanismo distinto del planteado por la vida social en occidente que ubica al sujeto dentro del conocimiento y su resultado es un sujeto egoísta, encerrado en sí mismo, en el yo - ismo. El aspecto esencial que nos muestra Lévinas es la presencia del rostro del Otro. En el Otro es donde se encuentra la socialidad y que nos permite constituirnos como sujetos. Allí se encuentra su crítica y sus discrepancias con las filosofías que solo se dedican a presentar un análisis histórico del sujeto. En consecuencia, el hecho fundamental que revuelve las significaciones terrenales, al aparecer el Otro como una presencia que viene hacia nosotros, en un presentarse que Lévinas describirá bajo la idea de que la manifestación del Otro es rostro, el Otro en cuanto rostro habla, expresa una palabra el cual es el primer discurso y que manifiesta una exuberancia, un algo más allá de cualquier realidad en el mundo. Dicha (palabra) es una súplica y una exigencia, un llamado a la responsabilidad, en que la conciencia pierde su primacía. El rostro es aquello que escapa a la conciencia, algo que en su alteridad absoluta invita a la renuncia del egoísmo y que en su manifestación abra un horizonte que es orientación y sentido, lugar de la ética y el humanismo. Y para mantener esa humanidad necesitamos de la Educación como el medio urgente de humanización. Para finalizar surgen algunas preguntas a considerar: ¿Cómo considerar que la tecnología y los medios que se producen como ser: computadores, celulares y otros no deben ser fruto para la interferencia de vernos cara a cara? y ¿cómo hacemos que la manifestación del otro debe ser muy relevante a la hora de construir una vida en común y una ciudadanía que tenga sentido el nosotros?

\footnotetext{
19 Gil Jiménez, P. (2006). En la Biografía de Emmanuel Lévinas se encuentra su trayectoria intelectual. Ver en la
} Web: http://de-autores.blogspot.com.co/2006/08/teora-tica-de-Ivinas.html 


\section{Referencias}

Bauman, Zygmunt. (2004). Ética Posmoderna. Argentina, Buenos Aires: Ed. Siglo XXI.

Freire, Paulo. (2006). Cartas a quien pretende enseñar. Madrid, España: Ed. Siglo XXI.

Gil Jiménez, Paula. (2006). Teoría ética de Lévinas. Cuaderno de materiales. Recuperado de http://www.filosofia.net/materiales/num/num22/levinas.htm

Gimeno, José. (2002). Educar y convivir en la cultura global. Madrid, España: Ed. Morata.

Habermas, Jurgen. (1999). La inclusión del otro. Barcelona: Ed. Paidos.

Hinkelammert, Franz. (2012). Lo indispensable es inútil. San José, Costa Rica: Ed. Arlekín.

Kymlicka, Will. (2015). Ciudadanía multicultural. Barcelona, España: Ed. Paidos.

Lévinas, Emmanuel. (1978). Totalidad e infinito. Salamanca: Ed. Sígueme.

Lévinas, Emmanuel. (1991). Ética e infinito. Madrid: Ed. Visor.

Lévinas, Emmanuel. (1993). Entre nosotros. Valencia: Ed. Pre - textos.

Lévinas, Emmanuel. (1998). Ética como filosofía primera [Trad. Oscar Lorca, 2006]. A parte Rei. Revista de Filosofía, (43). Recuperado de http://serbal.pntic.mec.es/ cmunoz11/lorca43.pdf

Lipovetsky, Gilles. (2008). La era del vacío. Barcelona: Ed. Anagrama.

Quintero, Walter. (2014). Emmanuel Levinas: una filosofía más allá del Ser. Cuadrantephi, (26-27), 1-10. Recuperado de http://www.javeriana.edu.co/cuadrantephi/zonaarticular/pdfs/N.26/Ponencias/Listos\%20para\%20subir/Una-filosofia-mas-alla-del-Ser,Walter-Quintero-(Corregido).pdf

Rojas, Enrique. (1995). El hombre Light. Santiago, Chile: Ed. Planeta Chilena Colección Fin de siglo.

Roldan, Concha. (2015). Leibniz: en el mejor de los mundos posibles. España: Ed. Bonalletra Alcompas S.L.

Touraine, Alain. (2006). ¿Podremos vivir juntos? México: Ed. Fondo de Cultura Económica.

Zubiri, Xavier. (1991). Inteligencia sentiente. Madrid: Ed. Alianza.

Zubiri, Xavier. (2003). El hombre y Dios. Madrid: Ed. Alianza.

Zubiri, Xavier. (1998). Sobre el hombre. Madrid. Ed. Alianza. 